\title{
Extreme Weather Events and Construction
}

SMEs: Vulnerability, Impacts, and Responses

\author{
Gayan Wedawatta*, Bingunath Ingirige \\ School of the Built Environment, University of Salford, UK \\ Keith Jones \\ School of Architecture \& Construction, University of Greenwich, UK \\ David Proverbs \\ Construction and Property Department, University of the West of \\ England, UK \\ * Corresponding author
}




\section{Abstract}

\section{Purpose (mandatory)}

The UK experienced a number of Extreme Weather Events (EWEs) during recent years and a significant number of businesses were affected as a result. With the intensity and frequency of weather extremes predicted in the future, enhancing the resilience of businesses; especially of Small and Medium-sized Enterprises (SMEs), who are considered as highly vulnerable, has become a necessity. However, little research has been undertaken on how construction SMEs respond to the risk of EWEs. In seeking to help address this dearth of research, this investigation sought to identify how construction SMEs were being affected by EWEs and the coping strategies being used.

\section{Design/methodology/approach (mandatory)}

A mixed methods research design was adopted to elicit information from construction SMEs, involving a questionnaire survey and case study approach.

\section{Findings (mandatory)}

Results indicate a lack of coping strategies among the construction SMEs studied. Where the coping strategies have been implemented, these were found to be extensions of their 
existing risk management strategies rather than radical measures specifically addressing EWEs.

\section{Research limitations/implications (if applicable)}

The exploratory survey focused on the Greater London area and was limited to a relatively small sample size. This limitation is overcome by conducting detailed case studies utilising 2 SMEs whose projects were located in EWE prone localities. The mixed method research design adopted benefits the research by presenting more robust findings.

\section{Practical implications (if applicable)}

A better way of integrating the potential of EWEs into the initial project planning stage is required by the SMEs. This could possibly be achieved through a better risk assessment model supported by better EWE prediction data.

\section{Originality/value (mandatory)}

The paper provides an original contribution towards the overarching agenda of resilience of SMEs and policy making in the area of EWE risk management. It informs both policy makers and practitioners on issues of planning and preparedness against EWEs. 
Key words: Construction, Extreme Weather Events, Resilience,

Small and Medium-sized Enterprises (SMEs), Vulnerability

Classification: Research paper 


\section{Introduction}

The UK has been affected by a number of Extreme Weather Events (EWEs) in the recent past. The 2005 heat wave, 2007 summer floods, and 2009 and 2010 heavy winter snowfall are some examples. Such weather extremes have lead to significant economic as well as societal costs. For instance, total economic cost of the 2007 summer floods was estimated at about f3.2 billion (Chatterton et al., 2010) whilst the insurance industry paid over $£ 365$ million in relation to 2010 cold winter ( $A B I, 2010)$. A significant proportion of these costs are associated with the business sector. For instance, in the case of 2007 floods, $£ 1$ billion was paid to businesses by the insurance industry $(A B I, 2008)$ and nearly $£ 60$ million was paid to businesses for property damage as a consequence of the 2010 heavy snowfall $(A B I, 2010)$.

Due to the nature of their operations, businesses operating in the construction sector have always been considered significantly vulnerable to weather extremes. Indeed, Mills (2003) identified the construction sector as one of the most vulnerable to climate change and EWEs. For example, the Centre for Economics and Business Research Ltd (CEBR) predicted an additional 2000-3000 business failures (in the UK) 
as a result of the disruptions caused by the heavy snowfall in 2009, with a significant proportion of these coming from the construction sector (McWilliams, 2009). This is in line with the dominance of Small and Medium-sized Enterprises (SMEs) within the construction sector; representing more than $99 \%$ of businesses in the sector (BERR, 2008), which are said to be highly vulnerable to disruptions caused by such events.

Whilst this finding alone is of concern to those managing the built environment, when one considers the important role that construction industry SMEs need to play in the wider recovery of a community following an EWE, the vulnerability and resilience of construction industry SMEs becomes of strategic importance to society as a whole. Thus, in the wider consideration of community resilience to extreme weather events, understanding the factors that affect the vulnerability, resilience, and adaptive capacity of construction SMEs is a significant factor in understanding the vulnerability, resilience and adaptive capacity of the community as a whole. To date few studies have been conducted to investigate how the construction SMEs perceive, are affected by, and respond to the risk of EWEs. 
This research was developed to investigate the effects of EWEs on construction SMEs, their existing coping strategies, and their perceptions of the risks posed by EWEs. The paper first presents a brief review of literature followed by the research method adopted. It then presents the findings of the research and discusses the implications of the findings on the vulnerability, resilience and adaptive capacity of construction industry SMEs. The paper concludes by making several recommendations for practice following from the findings of the survey and case study research.

\section{$2 \quad$ EWEs and construction sector SMEs}

EWEs can have both direct and indirect effects on the construction sector and those associated with it. Direct effects include disruption to site works as a consequence of the extreme weather event itself (e.g. the site might be flooded); indirect effects include disruption to site works as a consequence of the secondary effects of an extreme weather event (e.g. due to disruptions to deliveries and utility supplies through the supply chain) (Metcalf et al., 2009). This distinction is shown in Figure 1. However, whilst construction industry SMEs have been aware for many years of the direct affects that adverse weather could have on their operations, 
and indeed have developed project programming strategies to deal with such eventualities, there is less evidence to suggest that they are prepared for extreme weather events as a consequence of climate change or have considered in detail the indirect impacts to their operations of disruptions to their supply chain (Berkhout et al., 2004). This, when combined with the fact that construction sector SMEs were found to be the least prepared in terms of business continuity planning (only about $20 \%$ of construction sector SMEs had a plan to deal with business interruption compared to the other industry sectors surveyed in; manufacturing, retail, business/financial services, transport, and land based SMEs) (Norrington and Underwood, 2008) leaves them vulnerable to the consequences of an extreme weather event. In essence, construction industry SMEs do not appear to recognise the seriousness of current extreme weather events or to have appropriate risk assessment frameworks in place to assess their vulnerability, resilience and adaptive capacity to more extreme events that may occur as a consequence of climate change. It should be noted that such criticisms are not restricted to construction industry SMEs but have been observed across the range of organisations exposed to a range of extreme weather events and other natural hazards (Tierney and Dahlhamer, 1996; Alesch et al., 2001; Yoshida and Deyle, 
2005; Crichton, 2006; Dlugolecki, 2008).
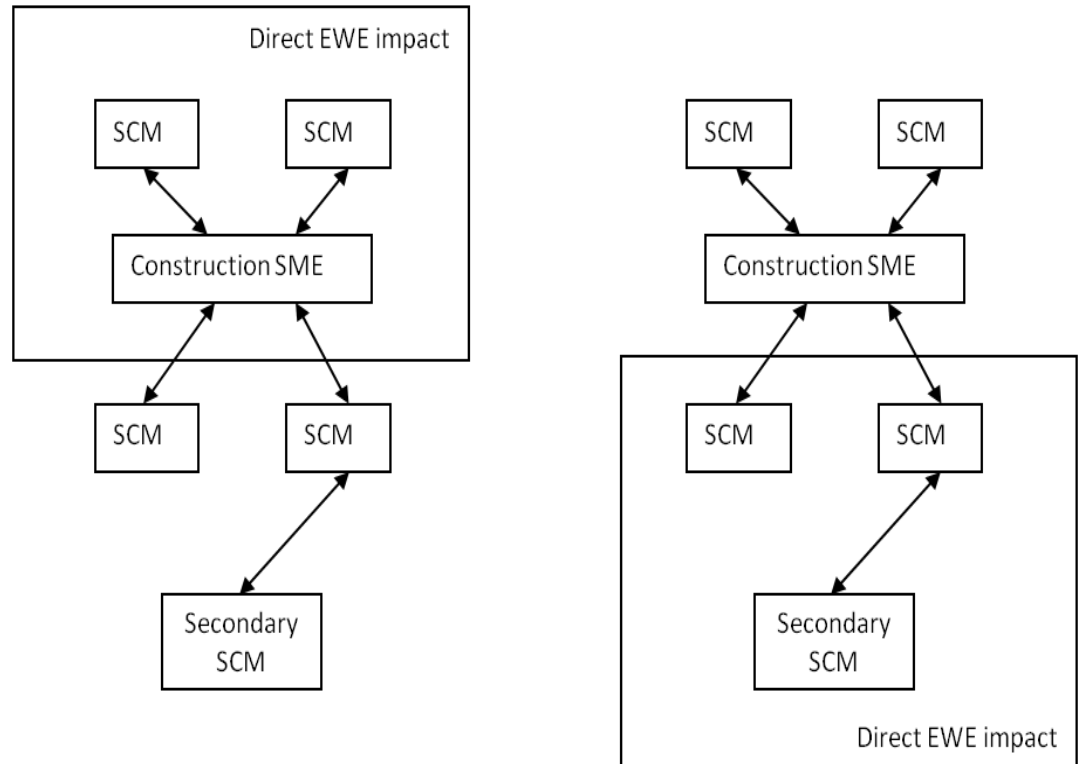

Figure 1 - Relationship of Construction SMEs and supply chain members (SCM) in relation to EWEs - Adapted from Zhang et al (2009)

Vulnerability, resilience and adaptive capacity are concepts that are increasingly used to interpret the impacts that climate change and EWE's are having on the built environment. Whilst there is considerable debate over the definitions (Gallopín, 2006; Cutter et al., 2008), for the purpose of this paper and in the context of business contingency/disaster recovery planning: vulnerability is the risk to a system by external forces or hazards (EWEs) that are beyond the normal range of variability under which the system operates; resilience is the ability of the system to cope with such forces or hazards and return to its normal operating status once they have been 
removed; and adaptive capacity is the ability of the system to change to meet new conditions brought about by forces that fundamentally change the system (Adapted from Jones and Few, 2009()()). In an examination of business attitudes to extreme events, Berkhout et al (2004) found that an organisations response to signals about the impacts (actual or perceived) that an EWE may have on their operations in the context of their own, and their competitors performance (assessing their vulnerability). If a threat/opportunity is perceived they apply existing solutions to address any impacts and, if successful, they continue as normal (inherent resilience). Only if their interventions are unsuccessful do they invest effort to find 'new' solutions to the problems and seek evidence to measure their success (their adaptive capacity). Based on this theory Berkhout et al (2004) developed a 4 stage decision-making framework based around: risk and opportunity analysis; strategy setting; implementation; and integration. However, when evaluating the model against climate change scenarios Berkhout et al (2004) found that:

- organisations found it difficult to recognise and interpret climate change stimuli;

- because of the weaknesses and ambiguities in climate change stimuli, trial and error experimentation with 
existing operating procedures were unlikely to yield satisfactory results;

- organisations found it difficult to assess the advantages and disadvantages of alternate adaptation strategies; and

- organisations found it difficult to directly measure feedback on the impact that the adaptation has had on organisational value.

Similar findings to the above have been identified by other authors who found that: a lack of forward planning; lack of capital for recovery; ineffectual interactions with national agencies; infra-structure problems (Runyan, 2006); individual attitudes and organizational culture (Petts et al., 1998); access to expertise; perceived exposure to risk (Yoshida and Deyle, 2005); lack of integration of the construction sector in disaster risk management in the UK (Bosher et al., 2007); and the relatively low importance assigned to climate change and EWE's by the construction sector (Harty et al., 2007), all contributing to a general inertia amongst organisations to consider resilience to EWEs. Thus, this raises questions as to whether current approaches to business contingency/disaster recovery planning can really deliver increased resilience and enhanced adaptive capacity in response to vulnerabilities 
induced by climate change. Given the predicted increase in the intensity and frequency of EWEs (Stern, 2007), the construction sector needs a new way of viewing the risks and developing business contingency plans, both from a business survival perspective and as a major stakeholder to wider community recovery following an EWE. Indeed, the construction sector needs to recognise that it has a significant role to play in delivering a resilient built environment. This requires a greater degree of organisational resilience, awareness, and proactive response of construction SMEs against EWEs.

\section{Research method}

\subsection{Research questions}

The research was developed to investigate three research questions:

- what are the effects of EWEs on construction SMEs?

- what are their existing coping strategies?

- how do they respond to the risk of EWEs?

In order to investigate these questions a mixed method research design was adopted (Figure 2). A mixed method research choice as described by Saunders et al (2009) will provide a better understanding of the issues being 
investigated. Creswell (2003) identified mixed method approach as "one in which the researcher tends to base knowledge claims on pragmatic grounds", and in which the researcher uses both quantitative and qualitative data to best understand the research problems being investigated. Curran and Blackburn (2001) identified that mixed method approaches are common in small business research and as capable of deriving benefits from triangulation and characteristics inherent to both quantitative and qualitative approaches. Dainty (2008) calls for methodological pluralism in construction management research, and identifies that adopting a diversity of approaches will increase understanding of the complex network of relationships pertinent to the industry. A similar viewpoint has previously been put forward by Love et al (2002). Use of a mixed method approach in this research was considered appropriate to further enhance knowledge of the research issues being investigated, but also in answering the call for a multi-paradigm approach to construction management research as opposed to the traditional positivist approach. An exploratory questionnaire survey was conducted to identify the scope of the issues under investigation, and two in-depth case studies of construction SMEs were developed to examine key issues in detail. 


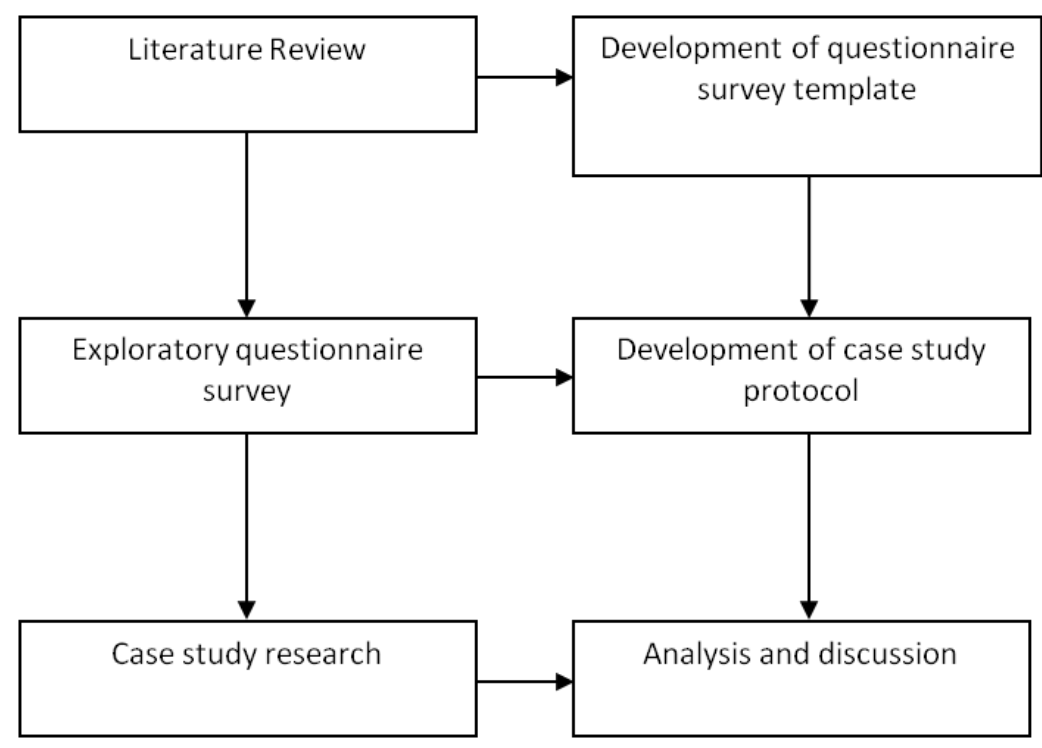

Figure 2-Research method

\subsection{Questionnaire survey}

The review of literature informed the preparation of the questionnaire survey template for data collection. The survey was specifically aimed at identifying the effects of EWEs on SMEs and the coping mechanisms implemented by SMEs in general. In broad terms, the aim was to investigate the overall resilience of SMEs to EWEs. The questionnaire survey was conducted as an online survey among the SMEs located in the Greater London area through the Federation of Small Businesses (FSB). The survey included 20 construction sector SMEs (out of a total of 140 SMEs) ranging from general contractors to architects and other built environment professionals. The survey was targeted at senior managers in the various organisations. The total SME sample is discussed 
separately; e.g. see Wedawatta et al (2010), only construction SMEs are considered here as the focus is on construction SMEs.

\subsection{Case study}

Following the questionnaire survey two in-depth case studies were developed to explore the context within which construction SME's interpret and respond to EWEs. The first case study was a principal building contractor (SME1) and the second a civil engineering subcontractor (SME2). Both SMEs are medium-sized businesses employing between 50 and 249 employees and are well established construction organisations that have been in business for several decades. In each case, a construction project which had been affected by a recent EWE was studied to obtain an understanding of on-site issues related to EWEs. The projects studied were (SME1) a residential development (P1) and (SME2) a land remediation and earthworks project (P2). Semi-structured interviews were used to collect data from both the senior management and site management of the case study organisations. Interview questions consisted of themes addressing: the impact of recent EWEs on general business continuity and the selected projects; how SMEs respond to the risk of EWEs; their perceptions of risk; and their relationship with their supply 
chain (in relation to EWEs). The questionnaire and case studies were developed between May 2009 and June 2010 .

\section{Findings}

\subsection{Survey findings}

Impacts of EWEs

Out of the 20 construction sector SMEs surveyed, $75 \%$ had experienced at least one type of EWE since 2005. Heavy snowfall (65\%), strong rainfall (although not flooding) (35\%) and extreme temperatures (20\%) were the main extremes that had affected these organisations.

The survey results also suggest that the heavy snowfall that affected the UK (and London in particular) in February 2009 (BBC News, 2009) had a major impact on the SMEs in the region (survey was conducted May-July 2009), although the severity of the impact was not consistent across all respondents ( $14 \%$ classified it as a major impact; $86 \%$ as a minor impact).

This biggest effect of an EWE on construction sector SME's was non attendance of employees (53\%) followed by a loss of sales / production; a reduction in employee productivity; disruptions to access to premise (33\%); and a decrease in 
turnover/profits (27\%) (see Figure 3).

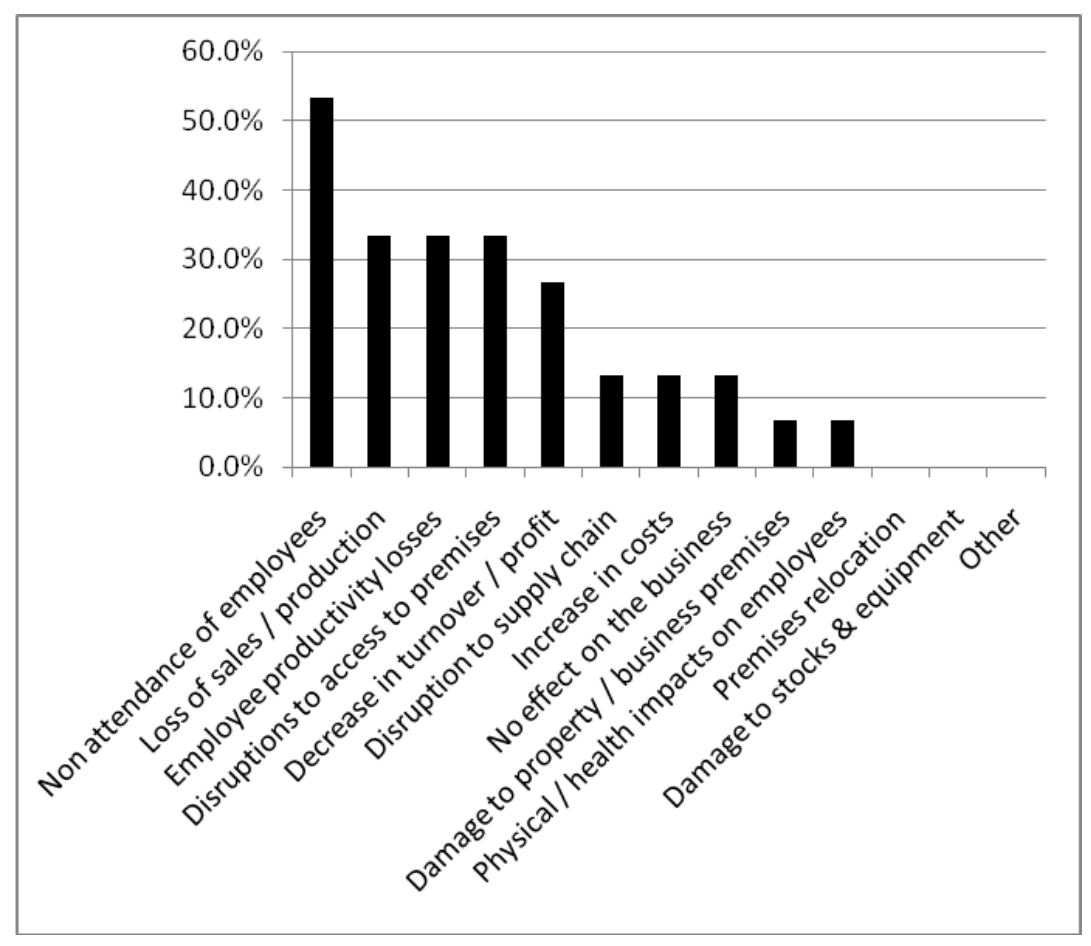

Figure 3 - Effects of EWEs on construction sector SMEs

Taking the findings presented in Figures 3 and 4 together it could be argued that the impacts reported by respondents are more likely to be associated with their last EWE experience rather than an objective assessments of the risks associated with EWE's. This would reinforce the view expressed by Desai and Jones (2010) who, in an extensive study of facilities managers' attitudes to EWE's and climate change, identified personal experience of an event (aligned with its severity) as a factor in informing a manager's response to the risks posed by such an event and Berkhout et al (2004) who found that SME's found it difficult to interpret climate stimuli unless they had an 
appropriate frame of reference.

Initially respondents only identified EWE's as having a minor effect on their supply chains (Figure 4). Only about 13\% identified that they have experienced supply chain related disruptions due to EWEs. However, a subsequent question which required respondents to detail the supply chain related disruptions experienced, recorded a very high response rate (47\%). The SMEs noted examples such as longer transportation times (40\%), inaccessible road networks (33\%), having to delay supplies coming in (33\%) and failure of businesses in their supply chain (20\%) as disruptions that mostly affected their supply chain. The fact that these were not reflected in response to the previous question may be attributed to the lack of understanding on the direct and indirect effects of extreme weather. Although the importance of supply chain related disruptions in relation to EWEs is often highlighted, SMEs seem to focus mostly on direct impacts but not on indirect impacts such as supply chain disruptions.

\section{Coping strategies}

The majority of construction sector SMEs (75\%), whether or not they had experienced a previous EWE (of any magnitude), did not adopt any coping mechanisms to protect their business against the impacts of EWEs. This is consistent with the finding 
of Berkhout et al (2004) who found that SME's found it difficult to assess the advantages and disadvantages of alternative adaptation strategies unless they had experienced severe disruption. Where construction sector SMEs have implemented coping mechanisms these have tended to be at the more strategic (business) level: online data backup (12\%); having property and business disruption insurance (12\%); and developing business continuity plans (6\%).

The construction sector SMEs surveyed did not seem to consider EWEs as a potential risk to their business activities. This could be due to the nature of the construction process, where disruptions to site practice as a consequence of inclement weather is dealt with at the project level rather than at the organisational level. If this is the case then this is again consistent with the findings of Desai and Jones (2010) who identified impact (or severity) of an event as a factor in attitudes towards risk.

\subsection{Case study findings}

\section{Impact of extreme weather}

During recent years SME1 has experienced heavy snowfall and extreme low temperatures at their sites. SME2 has experienced heavy snowfall and flooding, as well as, both high and low extreme temperatures. The two selected projects; P1 
and P2, were both affected by heavy snowfall between December 2009 and January 2010 (See Table 1). Additionally P1 was affected by extremely low temperatures. Disruption to P1 lasted approximately 4 weeks, whereas P2 was affected for approximately 1 week. As a consequence of the EWEs (and associated economic downturn in the economy) both SMEs experienced significant financial hardship. SME1 estimated a drop in their monthly average turnover (for the whole company) from f1.5million to f0.4million during January February 2010. This was over and above the anticipated turnover reduction during the Christmas and New Year period due to construction site closures. The primary impacts for SME 2 were loss of turnover and additional costs associated with implementing additional controls (e.g. having to double the frequency of meetings between site management and senior management during and after the events) and extension of time granted to cover the disruption, without any reimbursement of overheads for the period.

Table 1 - EWEs experienced by case study SMEs and the construction projects studied

\begin{tabular}{|c|c|c|}
\hline Entity & Description & EWEs that have caused a \\
& & significant impact recently \\
\hline
\end{tabular}




\begin{tabular}{|c|l|l|}
\hline SME1 & Building contractor & Heavy snowfall, extreme \\
& & low temperatures \\
\hline P1 & Residential building & Heavy snowfall, extreme \\
& construction project & low temperatures \\
\hline SME2 & Civil engineering & Heavy snowfall, flooding, \\
& subcontractor temperatures \\
\hline P2 & Land remediation and & Heavy snowfall \\
& earthworks subcontract & \\
\hline
\end{tabular}

\section{Coping strategies - SME1}

SME1 has identified that several decisions implemented, having commercial advantages in mind, have lead to reduced impact to their business from the recent EWEs. Therefore, SME1 has identified these as possible coping strategies that would reduce the impact on their business of similar events in the future. Most of SME1's site labour requirements were outsourced and paid on a measure and pay basis. In essence, SME 1 has transferred a large proportion of the financial risk to labour only subcontractors. Further, terms for employing their own site workers have been amended to enable the company to temporarily lay off workers for a short period of time at short notice. Although this has been allowed due to variations in workload, it has enabled the company to save a 
considerable amount of money during the disruptions caused by extreme weather conditions in $\mathrm{P} 1$. This approach is similar to that identified by Berkhout et al (2004) who noted similar instances where commercial decisions have lead to improved organisational resilience.

In addition to the transfer of financial risk, the senior management of SME1 was also keen to learn operational lessons from other countries that regularly experience weather similar to that which affected P1. To this end senior management had began to examine how Canada carries out construction activities. In addition to examining approaches to pricing, scheduling and methods of construction, they are also examining how Canadian construction SMEs were able to continue working through similar weather conditions. Although this work is ongoing SME1 believes that they can improve their resilience to similar EWE's in the future by changing their working practices. Finally, SME1 is also examining how their competitors dealt with the heavy snow as they are aware that similar companies will be more successful at coping with the EWE and mitigating the risk. Again, both these approaches are similar to those identified by Berkhout et al (2004).

\section{Coping strategies - SME 2}


In P2, SME2 also suffered significant financial loss as a consequence of restricted site operations for about 1 week, due to heavy snowfall. Being a specialist subcontractor, SME2 supplied all the plant, machinery, material and labour in P2. As such, SME2, unlike SME 1, was not in the position to transfer the financial loss to their downward supply chain partners. As such, they had to bear the full impact of the disruption.

Following the disruption, SME2 was keen to improve their resilience to future EWEs, and in particular develop coping strategies that can improve their preparedness. To this end, SME 2 is examining the contractual terms and conditions under which it takes on work. According to clause 60.1(13) of New Engineering Contracts 3 (NEC3), a weather event can lead to compensation if it is "shown to occur on average less frequently than once in ten years" (NEC, 2005). It further states that "only the difference between the weather measurement and the weather which the weather data shows to occur, on average, less frequently than once in ten years is taken into account in assessing a compensation event". It suggests that weather data that goes 10 years back has to be considered when determining inclement weather. Although the NEC3 condition related to weather extremes is much clearer than some of the other standard conditions of 
contract, SME2 still found it difficult to establish how to allow for winter snowfall in future contracts, having experienced back to back heavy snowfalls. Their main concern is how to establish a baseline for heavy snowfall in future projects, so as to minimise negative impacts of heavy snowfall on its projects, minimise contractual disputes whilst preserving their ability to come up with competitive bids for projects.

\section{Discussion}

The results showed that a significant number of SME's surveyed had experienced EWEs in the last 5 years, causing a range of effects on their businesses. However, experiencing an event had not led them to adopt a broad range of coping strategies against such events. This contradicts what other authors; see, for example, Heliview Research (2008), UKCIP (2009), and Kreibich et al (2010); have found in relation to SMEs/businesses in general. The reasons for this could be;

a. Construction SMEs do not see EWEs as out of the ordinary as weather has always affected the construction industry at the project level. It was also mentioned by the senior management of the SME2 that there is concern about 'adverse' weather more so than 'extreme' weather. Construction SMEs may tend to consider weather 
extremes as norms within the industry, considering the nature of its operations, and will utilise accepted standard practices to ensure business continuity, rather than employing radical coping strategies against EWEs.

b. The severity of the events that the SMEs have experienced was not significant enough to cause a major disruption to the business. Therefore, SMEs may tend to consider EWEs more as an annoyance than a threat to the future of the company. It is noteworthy that only about $14 \%$ of SMEs in the survey reported that they had a significant impact from the EWEs experienced. Consequently, this might have directed them not to consider implementing coping strategies. However, the case study SMEs were more concerned about the risk of EWEs and have identified several coping strategies, as they have experienced significant impacts of EWES recently.

Where the SMEs developed new coping strategies, these were an extension of their existing approaches for risk management/ transfer rather than radical approaches to minimise the impacts of future EWEs. For instance, SME1 has identified how their existing risk transfer mechanisms have helped them to minimise the impacts of recent EWEs and are 
interested in exploring further options. This is in line with what Berkhout et al (2004) found in UK house-building companies, where it was found that adaptation options for changing climatic conditions are likely to be affected/intervened by adaptation options for other external pressures (e.g. changing market conditions).

Although the case study organisations have begun to consider the threat of EWEs to their construction projects more seriously, this is due to their experience of recent EWEs, rather than due to a consensus that such EWEs could increase in number and severity in the future. Hence, their actions tend to be more reactive rather than being proactive. It is therefore important that the link between EWEs and climate change is established in the mind of senior management, leading them to implement a broad range of strategies to counteract the risk of EWEs. If the senior management do not see the link between the climate change and EWEs, they are unlikely to accept that things could get much worse and as such would not take radical action within their organisations. Thus, when a serious EWE strikes they will be caught unprepared and will experience serious negative consequences to their business continuity. More importantly, they will be unable to assist the wider community to recover from the event, leading to 
societal consequences. Similarly, the SMEs should recognise both the direct and indirect effects of EWEs on their businesses, hence widening the scope further to include supply chain disruption.

In order for construction SMEs to radically respond to the risk of EWEs, a better way of integrating the potential of EWEs into the initial project planning stage is required. This could possibly be achieved through a better risk assessment model supported by better EWE prediction data. Such a new risk framework model has to present the impacts of EWE hazards relative to a frame of reference that the business understands and can associate with. Vulnerability and coping capacity can be represented graphically on a risk impact grid where this will allow the business to evaluate the coping strategies that would lower the level of risk. This type of a framework is currently being developed through participatory studies with SMEs.

\section{Conclusion}

The UK has been affected by a number of extreme weather events and due to the effects of climate change the number and severity of these EWEs are set to rise in the future. Studies have shown that the impact of EWEs on the business sector in 
general has been significant. With the predicted rise in the number and severity of EWEs their vulnerability and exposure to risk is set to further increase. Although the vulnerability of the business sector due to EWEs has been well recognised, some of the current theories indicate that very few businesses will undertake proactive measures to overcome any future risks. In the construction industry, this problem is further aggravated due to the existence of a significant number of small and medium size enterprises. This research was developed to investigate the effects of EWEs on the vulnerability of SMEs in the construction industry and to explore both their existing responses to EWEs and their likely behaviour amidst the future predictions of EWEs. The research identifies the value of a risk framework model that will link a future hazard caused by EWEs with the level of vulnerability of construction SMEs. It is anticipated that such a framework model will allow construction SMEs to make appropriate decisions with regard to the degree of response to a whole range of EWEs.

The study adopted a mixed research design method and conducted a literature review, an exploratory survey and 2 case studies in the area. Whilst in the main, the findings confirmed the existing theories that SME actions tend to be 
reactive (due to recent experience of EWEs) rather than being proactive (making radical changes now based on future EWE predictions and climate change), this research contributed to both theory and practice by taking the current knowledge to a new level. In terms of practice, the research identified construction SME specific actions, such as, methods of risk transfer, outsourcing of work, contractual issues that would enable the companies to improve both their pre contract bidding strategies as well as post contract cost and time management of their projects. These will ensure that their vulnerability is reduced and that they can sustain their businesses for a longer time. In terms of policy making, the study identified the importance of measures to generate more robust predictions of EWEs due to climate change so that it will enable the SME construction firms to make strategic decisions on risk transfer processes. The study also identified the complex nature of extreme weather event risk management. Impacts of EWE on businesses are not only direct. The indirect supply chain disruptions caused as a result of EWEs also contribute significantly towards the risk exposure of SMEs. These lessons will benefit the emergence of a risk framework model that helps the businesses to understand the impact of EWEs with confidence in relation to a specific frame of reference within their companies, so that the SMEs can 
make informed judgements on how to reduce their vulnerability and improve their adaptive capacity against EWEs. The ongoing participatory studies with the SMEs are orientated towards these goals.

\section{Acknowledgement}

The content of this paper forms part of a multi-disciplinary project into Community Resilience and Extreme Weather Events (CREW) being funded by the UK Engineering and Physical Sciences Research Council (EPSRC). The authors would like to acknowledge the contributions made by academics of partner universities for the general discussions that formed the background to this paper.

\section{References}

$A B I$ (2008) Insurance for Small Businesses: A guide to protecting your business, London, Association of British Insurers.

$A B I$ (2010) Insurers pay out $f 650$ million to help customers weather the coldest winter in thirty years. Available at http://www.abi.org.uk/Media/Releases/2010/03/Insur ers_pay_out_650_million_to_help_customers_weathe r_the_coldest_winter_in_thirty_years.aspx (Accessed 24/03/2010)

Alesch, D. J., Holly, J. N., Mittler, E. \& Nagy, R. (2001) Organizations at Risk: What happens when small businesses and not-for-profits encounter natural 
disasters. Small Organizations Natural Hazards Project, First Year Technical Report, University of WisconsinGreen Bay. Fairfax, Public Entity Risk Institute.

BBC News (2009) Businesses counting cost of snow Available at http://news.bbc.co.uk/1/hi/business/7864804.stm (Accessed 07/02/2009)

Berkhout, F., Hertin, J. \& Arnell, N. (2004) Business and Climate Change: Measuring and Enhancing Adaptive Capacity. Tyndall Centre Technical Report 11. Oxford, Tyndall Centre for Climate Change Research.

BERR (2008) SME Statistics for the UK and Regions 2007. Enterprise Directorate Analytical Unit, Department for Business Enterprise and Regulatory Reform (BERR).

Bosher, L., Dainty, A., Carrillo, P., Glass, J. \& Price, A. (2007) Integrating disaster risk management into construction: a UK perspective. Building Research \& Information, 35(2), 163 - 177.

Chatterton, J., Viavattene, C., Morris, J., Penning-Rowsell, E. \& Tapsell, S. (2010) Delivering benefits through evidence: The costs of the summer 2007 floods in England. Flood and Coastal Erosion Risk Management Research and Development Programme. Bristol, Environment Agency.

Creswell, J. W. (2003) Research design: Qualitative, quantitative, mixed methods approaches, 2nd edition, London, SAGE Publications.

Crichton, D. (2006) Climate Change and its effects on Small Businesses in the UK, London, AXA Insurance UK.

Curran, J. \& Blackburn, R. A. (2001) Researching the small enterprise, London, SAGE Publications.

Cutter, S. L., Barnes, L., Berry, M., Burton, C., Evans, E., Tate, E. \& Webb, J. (2008) A place-based model for 
understanding community resilience to natural disasters. Global Environmental Change, 18(4), 598606.

Dainty, A. R. J. (2008) Methodological pluralism in construction management research. IN KNIGHT, A. \& RUDDOCK, L. (Eds.) Advanced Research Methods in the Built Environment. Chichester, Wiley-Blackwell.

Desai, A. \& Jones, K. (2010) Examination of existing facilities managers attitudes to climate change. Proceedings of CIB W70 - FM in the Experience Economy. Sao Paulo, Brazil. September 2010.

Dlugolecki, A. (2008) Climate Change and the Insurance Sector. The Geneva Papers, 33(1), 71-90.

Gallopín, G. C. (2006) Linkages between vulnerability, resilience, and adaptive capacity. Global Environmental Change, 16(3), 293-303.

Harty, C., Goodier, C. I., Soetanto, R., Austin, S., Dainty, A. R. J. \& Price, A. D. F. (2007) The futures of construction: a critical review of construction future studies. Construction Management and Economics, 25(5), 477 493.

Heliview Research (2008) Climate change effects, Breda, Heliview Research.

Jones, K. \& Few, R. (2009) Community resilience to extreme weather events: A review of theory RICS Construction and Building Research Conference (COBRA) 2009. University of Cape Town, Soth Africa.

Kreibich, H., Seifert, I., Thieken, A., Lindquist, E., Wagner, K. \& Merz, B. (2010) Recent changes in flood preparedness of private households and businesses in Germany. Regional Environmental Change, 1-13.

Love, P. E. D., Holt, G. D. \& Li, H. (2002) Triangulation in 
construction management research. Engineering Construction and Architectural Management, 9(4), 294303.

McWilliams, D. (2009) Hit from the big freeze will be 2-3 thousand businesses going bust earlier. London, Centre for Economics and Business Research Ltd. Available at http://www.cebr.com/Resources/CEBR/The_cost_of_t he_big_freeze.pdf (Accessed 18/09/09).

Metcalf, G., Jenkinson, K. \& Johnstone, K. (2009) A changing climate for business. Oxford, UK Climate Impacts Programme.

Mills, E. (2003) Climate change, insurance and the buildings sector: technological synergisms between adaptation and mitigation. Building Research \& Information, 31(34), 257-277.

NEC (2005) NEC3: Option B: Engineering and construction contract Compensation events. London, NEC, Thomas Telford Ltd.

Norrington, H. \& Underwood, K. (2008) Climate change and small businesses: How directors are responding to the challenges of climate change - Research Findings 2008, Guildford, Climate South East.

Petts, J., Herd, A. \& O'HEocha, M. (1998) Environmental Responsiveness, Individuals and Organizational Learning: SME Experience. Journal of Environmental Planning and Management, 41(6), 711-730.

Runyan, R. C. (2006) Small Business in the Face of Crisis: Identifying Barriers to Recovery from a Natural Disaster. Journal of Contingencies and Crisis Management, 14(1), 12-26.

Saunders, M., Lewis, P. \& Thornhill, A. (2009) Research methods for business students, 5th ed., Harlow, 
Pearson Education.

Stern, N. (2007) The Economics of Climate Change: The Stern Review, Cambridge, Cambridge University Press.

Tierney, K. J. \& Dahlhamer, J. M. (1996) Business Disruption, Preparedness And Recovery: Lessons From The Northridge Earthquake. DRC Preliminary Papers, Disaster Research Center, University of Delaware.

UKCIP (2009) Small and medium enterprises - Vulnerability and resilience to extreme weather. A review for Oxfordshire County Council. Oxford, UK Climate Impacts Programme.

Wedawatta, G., Ingirige, B. \& Jones, K. (2010) Coping strategies against extreme weather events: A survey of SMEs in the UK. RICS Construction and Building research conference (COBRA) 2010 Université Paris-Dauphine, Paris.

Yoshida, K. \& Deyle, R. E. (2005) Determinants of Small Business Hazard Mitigation. Natural Hazards Review, 6(1), 1-12.

Zhang, Y., Lindell, M. K. \& Prater, C. S. (2009) Vulnerability of community businesses to environmental disasters. Disasters, 33(1), 38-57. 